Please do not remove this page

RMIT

UNIVERSITY

\title{
Transitioning to low carbon communities - from behaviour change to systemic change: Lessons from Australia
}

Moloney, Susie; Horne, Ralph; Fien, John

https://researchrepository.rmit.edu.au/esploro/outputs/9921864157901341/filesAndLinks?institution=61RMIT_INST\&index=null

Moloney, S., Horne, R., \& Fien, J. (2010). Transitioning to low carbon communities - from behaviour change to systemic change: Lessons from Australia. Energy Policy, 38(12), 7614-7623.

https://doi.org/10.1016/j.enpol.2009.06.058

Document Version: Accepted Manuscript

Published Version: https://doi.org/10.1016/j.enpol.2009.06.058

Repository homepage: https://researchrepository.rmit.edu.au

Copyright 2009 Elsevier Ltd. All rights reserved

Downloaded On 2023/04/26 21:51:08 +1000

Please do not remove this page 
Cite paper as: Moloney, S. Horne, R E. and Fien J. (2010) "Transitioning to Low Carbon Communities From Behaviour Change to Systemic Change: Lessons from Australia”, Energy Policy Dec. Vol. 38, Issue 12, p. 7614-7623

\title{
Transitioning to Low Carbon Communities - From Behaviour Change to Systemic Change: Lessons from Australia ${ }^{1}$
}

Moloney, Susie, Horne, Ralph E. and Fien, John

Centre for Design, RMIT University

susie.moloney@rmit.edu.au, ralph.horne@rmit.edu.au and john.fien@ @rmit.edu.au

\begin{abstract}
Transitioning to low carbon communities requires an understanding of community practices and resultant emissions, as well as the technologies, infrastructures and institutions associated with and accessed by communities. Moreover, it requires an understanding of the connections between these integrated system components, its dynamics, a defined transition, and potential 'levers' involved in 'transitioning'. This paper accepts the notion that 'levers' include programmes designed to achieve practice or behaviour change in households which result in less carbon intensive lifestyles, and focuses on the factors that shape human behaviour and influence householder energy consumption. Research to date by the authors and others indicates that a comprehensive socio-technical framework that considers both individual psychological factors as well as the systems, standards and norms under which individuals operate is fundamental to the development of successful strategies to shift towards low carbon communities.

A database has been compiled of over one hundred local programmes aimed at realising carbon neutral communities across Australia largely through approaches to behaviour change. This paper presents the findings of an analysis of these programmes, particularly with regard to the extent to which they take account of a socio-technical framework or understanding of domestic consumption behaviours and whether they are aware of or aim to influence changing standards and expectations around consumption practices within the home. While a number of exemplary community-based programmes adopt an integrated approach to addressing both technical and behavioural dimensions in the shift to low carbon communities, it was found that most fail to take sufficient account of the systems, standards and norms shaping consumption. Conclusions include directions for policy and programme design based on the study findings.
\end{abstract}

Keywords: behaviour change, socio-technical analysis, behaviour change programmes, low carbon communities

${ }^{1}$ This paper is based upon research conducted as part of the Carbon Neutral Communities: Making the Transition project and is supported by Australian Research Council Linkage Grant \# LP0775120. 


\section{INTRODUCTION}

The proposed timeframes for redressing the rise in global temperatures are becoming shorter, as each newly-released climate change report highlights additional evidence of receding polar icecaps, rates of deforestation and rising sea levels. Tackling the scale and complexity of climate change has prompted a whole range of responses from intergovernmental protocols and national and local greenhouse emission targets to carbon trading schemes and local community climate action projects. Central to much of the climate change debate is the consensus that changes to human actions and behaviours is required to make a 'transition'. Thus, appeals to reduce individual impacts on the environment are widespread with calls to measure one's own eco-footprint, recycle more, buy green products, use energy efficient lights and appliances, switch off at the wall, catch public transport, walk and bicycle more, and drive cars less. Media campaigns, websites, workshops, courses, discussion circles and information flyers are emerging from a wide range of sources. All are welded by a collective notion that a significant transition is required towards low carbon communities.

While accepting that there are many possible definitions of 'transitioning', for the purposes of this paper, we are concerned with transitions in social practice and behaviour which result in less carbon intensive lifestyles. The relationship between escalating consumption and waste and associated environmental impacts has become increasingly clear over recent years for, as stated by Jackson, "Consumer behaviour is key to the impact that society has on the environment" (2005: v).

The evidence linking human action and use of fossil fuels with climate change is stark. This can result in an understandable temptation to focus on human behaviour as the 'cause' of such actions. However, the 'problem' of human behaviour which leads to emissions needs to be placed within the wider contexts where social practices are undertaken. Norms and values shape practices, and so do infrastructures, institutional arrangements and systems of governance. Therefore, transitioning to low carbon communities requires an understanding of community practices and resultant emissions, as well as the technologies, infrastructures and institutions associated with and accessed by communities. Moreover, it requires an understanding of the connections between these integrated system components, their dynamics, a clearly defined transition pathway, and potential 'levers' to catalyse 'transitioning'. Such 'levers' include programmes designed to achieve practice or behaviour change in householder energy consumption.

While the need to take responsibility for personal actions is a common key message of such programmes, there is little agreement about the most effective strategies for achieving a transition through behaviour change. Indeed, there is not even agreement on the fundamental principles that ought to underlie such efforts with major splits between micro-sociological-cum-psychological approaches based upon social marketing and macro-sociological-cum-socio-technical approaches based upon structural and institutional reforms. For example, A Framework for Pro-environmental Behaviours published by the UK Department for Environment, Food and Rural Affairs (Defra) (2008) adopts a social marketing approach, with methods derived from the business world. This is similar to the approaches recommended by advocates such as McKenzie-Mohr (McKenzie-Mohr and Smith 1999) which target specific behaviours, immediate barriers and interventions to overcome those barriers. By contrast, a report by the World Wildlife FundUK challenges the widely adopted social marketing approach to behaviour change by arguing that it does not go far enough in addressing the fundamental shifts required in policy and lifestyles necessary to respond to climate change (WWF 2008). The WWF approach "reject[s] appeals to individualism" and the oft-cited personal benefits or social status resulting from adopting particular pro-environmental behaviours. Instead, it focuses on the motivations and values that are 'intrinsic' to people such as "personal growth, emotional intimacy or community involvement" which, it is argued, are more likely to lead to pro-environmental behaviour (WWF 2008:7). A third approach extends the rejection of individualism and the behaviouristic assumption of micro-sociological approaches and advocates the importance of the "socio-technical context" of human behaviour and the resultant need for changes in structural and institutional environment, which would normalise pro-environmental actions through 
systems of incentives, rewards and convenience (Strijbos 2006: 365). Unfortunately, regardless of the preferred approach to behaviour change and the proliferation of associated programmes, few are working as effectively as they might or on as widespread a front as is necessary for rates of energy use and greenhouse gas emissions to begin decreasing sufficiently for us to avert destructive climate change. This makes it necessary to explore ways to evaluate existing programmes and use these evaluations to inform appropriate policies and strategies to encourage low carbon practices (UK Green Building Council 2008).

This paper is based upon an analysis of a data base of over one hundred programmes in Australia, which seek to promote energy conservation and efficiency largely through behaviour change. It focuses on the key aims of these programmes and the types of approaches and techniques used to address energy conservation and efficiency in the home. Of particular concern is the extent to which these programmes address key factors that are important ingredients in ensuring long-term, systemic change in energy use. These factors are developed from an analysis of two bodies of literature. The first comprises theories and methods of environmental behaviour change, and extends across the health, psychology, marketing and education fields. The second is the broadly termed 'socio-technical' literature which challenges the dominant techno-economic paradigm of the former, and argues for an integrated approach to understanding and resolving the technology-behaviour relationship. Both literatures converge around an agreement that current commonly adopted individualised behaviour change strategies (such as market mechanisms) are not effectively reducing energy consumption. This paper brings these two perspectives together and uses themes from the convergence to review current practices in behaviour change programmes in Australia. Implications for policy and programme making are identified in the conclusion.

\section{BEHAVIOUR CHANGE AND CHANGING BEHAVIOURS: THE EMERGING GAPS}

\section{Behaviour Change Models}

Reviews of behaviour change theories and strategies reveal a wide range of theories and assumptions (O'Dwyer et al 1993, Jackson 2005, Kollmuss and Agyeman 2002, Shipworth 2000). These largely differ according to the variables they focus on and whether, for example, they are internal (micro-sociological) or external (macro-sociological). Internal variables are those that influence or shape what goes on inside a person's mind, such as awareness, knowledge, values, attitudes, behaviour, rational thought processes, emotional states, entrenched habits, etc. These vary between individuals and within an individual as a function of life stage and context. External variables are located in the physical, social and discursive environments in which a person lives. However, while there is no universally accepted theory of behaviour change, it is possible to identify a range of variables, which can impact on behaviour, depending on the context.

Jackson (2005) argues that a 'rational choice model' of consumer behaviour currently dominates thinking and practice in this area. This model assumes that human action is the result of a person logically weighing up the costs and benefits of different actions and choosing the option that maximises expected benefits. Jackson outlines three underlying assumptions in this model: (i) individual self interest is the appropriate framework for understanding human behaviour; (ii) 'rational' behaviour is the result of processes of cognitive deliberation; and (iii) consumer preferences are exogenous to the model, that is, they are taken as a given without further elaboration as to their origins or antecedents (2005:vii). The sorts of policy responses that flow from this model involve, first, providing information to ensure that consumers can make informed choices and, second, providing a mechanism for internalising costs associated with externalities in order to make them 'visible' to private choice. As a result, the use of information and pricing signals are key tools in the 'rational choice model'.

This model of consumer behaviour relates to the dominance of the 'techno-economic' model of change (discussed in the next section) where technological solutions are preferred and consumers are understood as 'autonomous individuals'. In the context of climate change strategies, the result is that there is both a preoccupation with technological solutions and use of technical, command and control, market based 
measures (IPCC 2001) and a focus on information, education, social marketing and other voluntary measures to influence individuals choices and behaviours (Dietz and Stern 2002).

Critics of the rational choice model argue that many of the choices people make are derived more from emotional responses rather than from cognitive or conscious deliberation (Jackson 2005, De Kirby et al 2007, Smith 2004, Costanzo et al 1986). The assumption of self-interest has also been challenged by critics who suggest that human behaviour is derived from social, moral and altruistic motivations in addition to self interest (Schmidt 2004). In particular, it is argued that the rational choice model tends to ignore the 'social embeddedness' of decision making where individual choices are continually being shaped and reshaped by the social contexts in which they take place (Shove 2003, Jackson, 2005, Guy 2006).

The preoccupation with individual motivations, values, beliefs and ways of influencing and shaping them is common across many behaviour change programmes. As a result, they rely on unproven assumptions and, thus raise important questions about the likelihood of their success. For example, it is possible to identify three assumptions in many environmental education programmes that correlate with those in many behaviour change programmes (Fien et al 2008). The first is that the right information will lead to appropriately responsible environmental behaviour. Information can be an important first step in prompting people to change their behaviour. However, information alone is unlikely to motivate changes as a matter of course. Information is also unlikely to result in sustained behavioural change beyond the life of a given campaign, since enthusiasm for 'new' behaviour or actions tends to wane and participation decays in the absence of continual reinforcement (O’Dwyer et al 1993).

The second assumption is that if people are presented with the facts, for example, about how their behaviour is affecting the environment, they will respond rationally and change to other behaviour. On the contrary, evidence suggests that responses vary according to their contexts, cultures and emotional states, and with increasing knowledge about climate change and its impacts, responses can vary from disinterest and disempowerment to scepticism and fear (Finger 1993, Australian Psychological Society 2008). The implications for communication campaigns, particularly around climate change, are that highlighting impending doom and tragedy can have paralysing rather than empowering effects. Furthermore, even if paralysis is avoided, many behaviours are not overtly 'chosen', and may be better termed 'habits' or practices, which daily lives are 'locked into' and, therefore, difficult to change. As Jackson argues "Habit is one of the key challenges for behavioural change policy since many environmentally significant behaviours have this routine character" (2000:ix). Hence, the daily routine of private car multi-trip commuting may be recognised as more 'locked in' practice rather than 'behavioural choice', where there are few economic or infrastructural choices to move, use other forms of transport or spend more time on the activity. Similarly, in the home, while daily showering and changing of clothes is the accepted norm, there are few options to 'change behaviour' and use less hot water for such activities without risking contravening these norms.

The third assumption of many programmes relates to an assumed primacy of individual over collective behaviour change. Maniates has described this in political economy terms as the "privatisation and individualisation of responsibility for environmental problems" which "shifts blame from state elites and powerful producer groups to amorphous culprits like 'human nature' or 'all of us"' (2002:57). This mode of governance, described by some commentators as a form of 'ecological modernisation' or 'ecoefficiency' (Bulkeley et al. 2007), passes responsibility to consumers to individually purchase more energy-efficient or 'environmentally friendly' goods (Hobson 2006). This limits behaviour change interventions to providing moral persuasion or cost incentives to encourage the uptake of more efficient technologies or, alternatively, simply to wait for energy price increases in the mistaken expectation that these will encourage households to reduce consumption - a position openly advocated by 'rational economic' policy agencies (e.g. Productivity Commission 2005). This effectively ignores the considerable body of research derived from Giddens theory of structuration, which explains how agency and structure relate to each other, and draws a distinction between 'practical' and 'discursive' 
consciousness. Where the former relates to habits and routines, the latter to intentional and goal oriented behaviours (see next section). Thus, such approaches also miss the significance of the insight that where information and social marketing techniques may be relatively effective in influencing behaviours that require little confidence or skill (i.e. within practical consciousness), deeper changes to habits and lifestyles (i.e. within discursive consciousness) require strategies that engage individuals at a deeper level and that can catalyse both the commitment and sense of self-efficacy to adopt consistently (de Young 1996; Heimlich and Ardoin 2008).

Considerations such as these raise a number of questions about the choice of techniques used in behaviour change programmes, including: the appropriateness of the focus on the individual rather than the collective, the role of social norms, practices and habits, and the extent to which behaviour change programmes explore what is shaping and influencing particular behaviours they seek to change. Where many current social marketing approaches frame their campaigns around appealing to individualistic goals such as social status and financial savings, WWF (2008) recommends framing campaigns around more 'intrinsic values' such as personal growth and community involvement which they argue would lead to more successful outcomes. This potentially introduces social norms into the equation, recognising that behaviour is socially constructed and therefore needs to be considered at the collective or social level.

\section{Bridging the Gap: A Socio-technical Approach}

The acknowledgement of the relevance of social values is a step forward in the behaviour change endeavour. However, it does not overtly recognise the fact that "[c]hanging people's attitudes without taking the behaviour-steering aspects of technology into account does not automatically lead to behaviour change" (Slob and Verbeek, 2006:5). Guy (2006) points out that techno-economic dominance results in a particularly functional approach to technology which virtually ignores the social context in which technologies emerge and is shaped by the behaviours of those who will be using them. In other words, "[t]he use of technology of all sorts is embedded in a socio-technical context" (Strijbos 2006: 365).

A significant body of research has accumulated, particularly over the last decade, indicating the importance of understanding the role of context and technology in shaping behaviour relating to energy use and, vice versa, the role of behaviour and routine in shaping the use of energy-related technologies (e.g. Lutzenhiser 1993, Shove, 2003, 2004, 2006, Chappells et al. 2000, Shove and Ward 2001, Wilhite et al. 2000, Van der Waals et al. 2003, Chappells and Shove 2005, Shove et al 2007, 2008). This largely macro-sociological body of research has argued for the replacement of the techno-economic framework with a socio-technical framework for understanding the technology-behaviour relationship (Guy 2006). A socio-technical framework situates technology and technological innovation in the social contexts in which they emerge and explores how and why a particular society shapes or generates the technologies that are produced. In this framework the analysis of energy related issues does not focus on "individualist explanations of technological innovation (the rational energy consumer)". Indeed, it "rejects any form of technological determinism (technical innovation as handmaiden to an energy efficient economy), and, critically refuses to distinguish prematurely between technical, social, economic, and political aspects of energy use" (Guy 2006: 650). Importantly, this approach does not take particular social standards and expectations as a given. Rather, it seeks to interrogate their construction and reconstruction and examine the implications for the social practices of consumption in all its dimensions. As Shove contends our concerns ought to focus on "the relation between consumption and convention, technology and practice" (Shove 2003:199).

In socio-technical analysis, energy related consumption is understood as being shaped to an extent by the modes or systems of provision of utility and energy services (Chappells et al 2000: 26). In this context, there is a dynamic relationship between agents of 'utility sectors' who provide energy, water and waste services and the consumers of those services. Domestic consumption is then understood within its context of "serving and being served by collective socio-material systems" (Chappell et al 2000:12). This view importantly does not target or isolate individual behaviours but rather views behaviours as socially 
constructed by the socio-technical systems in which they emerge and are reproduced. Thus, "actions and ways of using technology are conditioned by the context and steered by common 'practices' that take on a definite form in social interaction between people. To attain a more systematic grasp of the relation between technology and behaviour it is therefore necessary to have a closer look at the concept 'practice' (Strijbos 2006:367).

The use of the concept 'practices' in socio-technical analysis, as opposed to behaviours, indicates a rejection of the emphasis on individually focused behaviour change but rather begins with the collective or social context shaping and framing our daily actions. Practices are embedded in a range of sociotechnical systems which constitute a diversity of institutions, regulations, infrastructures and technologies. They are also framed and shaped by the norms and values of the societies and contexts in which they take place. Thus, Shove, for instance, places the cultural aspects of domestic consumption practices as central to her analysis. This includes focusing attention on how activities are constructed and reproduced, a concern that is largely ignored by the 'technocratic approach' of demand management strategies adopted by most governments and behaviour change programmes (Shove 2006: 293). Framing practice in this way reveals that it is "rather unrealistic to assume that directing policy instruments and measures only towards citizen-consumers could prevent or reduce the environmental impacts of household consumption" (Chappells et al 2000:13).

\section{TOWARDS LOW CARBON COMMUNITIES: A FRAMEWORK FOR ANALYSIS}

Five key themes emerge from this review of the behaviour change and the socio-technical approach to understanding energy use-consumption: (i) framing behaviour and social practices; (ii) beyond barriers and constraints; (iii) approaches to empowerment and agency; (iv) the need for systemic change; and (v) the path forward through learning and integration. These themes presage a number of questions, not just about current approaches to behaviour change, but also about current approaches to social and systemic change and the role of behaviour change programmes as part of that. The nature of these issues and questions are summarised in Table 1. They are discussed in this section and then used to explore the extent to which some of these issues are being addressed in current behaviour change programmes in Australia.

(i). Framing Behaviour and Social Practices: The 'why and what' of behaviours is important, and assumptions about rational motivations are likely to obscure reality. This also raises the importance of 'intrinsic' and 'extrinsic' values, with the suggestion that an activity which upholds intrinsic values such as personal growth, emotional intimacy or community involvement is more likely to lead to a higher level of engagement than those that appeal to extrinsic values such as the acquisition of material goods, financial success, physical attractiveness and social recognition (WWF 2008:24). Beyond overt motivations lies the arena of social norms and practices, which requires that account is made of the importance of social norms and standards, for example, of comfort, cleanliness and convenience, in understanding behaviour or practice (Shove 2003). Interventions such as behaviour change programmes may be more successful if they include considerations of both technologies and consumers, and the dialectical relationships between them. Placing social practices (rather than behaviours or technologies) at the centre of analysis requires that the context of doing is recognised as at least as important as the doing itself.

(ii) Beyond Barriers and Constraints: While there are criticisms of the community based social marketing approach, mapping behaviours is an important precursor in achieving behaviour change - and motivations and values must not be overlooked in that process. Winefield provides a useful summary of some of the key barriers that need to be addressed when working towards achieving behaviour change (Winefield 2005:9) as follows:

$\circ$ Willingness to act

- Low level behaviours i.e. habitual behaviours

$\circ$ Norms and Habits - including social factors 
- Convenience - relates to external conditions

- Cost - not necessarily financial could be time (relates to convenience)

- Psychological effects - environmental problems are more distant and less tangible which may reflect on attitudes, cognitive dissonance between attitudes and behaviour; the commons dilemma relates to the reluctance of an individual to act which relates to social factors

- Lack of agency - or a lack of a sense of personal control and relates to perceived capacity of the individual to act (and make a difference)

We must look beyond barriers, in so far as this means things which stand in the way of an intentional behaviour change. Some of the factors identified above relate to routine and habit formation, the social contexts in which we live and our sense of control or agency in affecting change through our behaviours. While these may present 'barriers' they also present interrelated patterns of activities which are not obstacle-like and may not therefore be readily identifiable as barriers, and instead resemble a patchwork of related factors. The language of barriers suggests a need for bypasses, which could lead to subsequent new barriers, whereas a more connected language of 'factors' or some such speaks more clearly to the need to address change in a systemic context rather than as a simplistic individual problem solving one.

(iii) Approaches to Empowerment and Agency: People's sense of control and agency is an important psychological factor motivating behaviour and is derived from both internal and external variables such as a person's education, income and social status as well as their social, institutional and regulatory context. This raises questions about the role a behaviour change programme plays or can play in addressing both the internal and external variables affecting empowerment in a given context. Also, given the collective nature of social context and norms (as per (i)), there is a logical need to include participants in the design and delivery of strategies which aim to reset the collective social-material system, thus providing a degree of empowerment, ownership and collective control.

(iv) The Need for Systemic Change: Is individual behaviour change an adequate response or are other programmes and strategies (e.g. social, institutional, infrastructural) required to support the changes required of individuals and communities? As Kaplan states, "Environmental campaigns must avoid 'blaming the victim' strategies. Individual behaviour change strategies are inappropriate if macro conditions exist which can be blamed for contributing to the problem or constraining the effectiveness of individual efforts (e.g. companies that do not provide ecologically friendly products, government inactivity)" (2000:500-501). This is an argument supported by many authors, including across the sustainable education field (Fien et al 2002). While instituting fundamental changes to the institutions, policies and regulations which govern and shape our behaviour may be an unrealistic task for a single behaviour change or education programme, it is essential that such programmes take account of the systemic context in their planning and delivery. It is not an adequate solution to expect participants to 'just try harder'.

(v) Paths Through Learning and Integration: The impact of social learning in communities can be significant in changing people's behaviour and motivating them into action (UK Green Buildings 2008). The Green Buildings report goes on to say that what is required are 'system binding agents' who work between grass-roots and mainstream to facilitate action at the grass roots level by ensuring top down support. There is a growing body of literature around social learning which has important implications for the field of behaviour change particularly around climate change issues (Leeuwis and Pyburn 2002, Keen et al 2005, Wals 2007, Brown 2008). Jackson (2005) contends that social learning may offer a path for sustainable consumption policy to address and re-negotiate habitual behaviour. A vital ingredient for changing habits, he argues, is to 'unfreeze' existing behaviour to raise the behaviour from a level of practice to discursive consciousness. This process is known to be more effective in a more supportive social environment (Jackson 2005). This raises questions about the how audiences are targeted and what approaches to education are adopted in behaviour change programmes as well as about the context in which programmes exist. 
Table 1: Framework for Analysis of Programmes

\begin{tabular}{|l|l|}
\hline Theme & Questions \\
\hline Framing Behaviour and Social Practices & $\begin{array}{l}\text { What assumptions are made about behaviour and } \\
\text { motivators for behavioural change? How are these } \\
\text { reflected in the techniques used eg. information, } \\
\text { workshops, goal setting etc? To what extent are } \\
\text { routines, practices and context explored or } \\
\text { identified as important in these programmes? } \\
\text { (Spectrum: from targeting individual behaviours to } \\
\text { understanding and scripting social practices, } \\
\text { norms and values) }\end{array}$ \\
\hline Beyond Barriers and Constraints & $\begin{array}{l}\text { What barriers and factors are identified and how } \\
\text { are they addressed? } \\
\text { (Spectrum: from individual behaviour specific } \\
\text { barriers to collective, institutional and regulatory } \\
\text { systemic factors) }\end{array}$ \\
\hline Approaches to Agency and Empowerment & $\begin{array}{l}\text { What support does the programme receive from } \\
\text { key agencies? How is the need for individual and } \\
\text { collective agency and empowerment recognised } \\
\text { and incorporated as a key component of these } \\
\text { programmes? } \\
\text { (Spectrum: from individually focused behaviour } \\
\text { change to collective capacity building) }\end{array}$ \\
\hline Paths Through Learning and Integration & $\begin{array}{l}\text { What technical and systemic factors are considered } \\
\text { in addressing change? How are they addressed? } \\
\text { (Spectrum: from individual focus to systems of } \\
\text { provision - changing light bulbs to accounting for } \\
\text { how, what and who constitutes the 'light bulbs } \\
\text { system') }\end{array}$ \\
\hline $\begin{array}{l}\text { What approaches to learning are adopted in these } \\
\text { programmes? } \\
\text { (Spectrum: from providing information to capacity } \\
\text { building and social learning) }\end{array}$ \\
\hline
\end{tabular}

\section{BEHAVIOUR CHANGE PROGRAMMES IN AUSTRALIA}

\section{Scope and Overview of Programmes}

The following presents an overview of the range of behaviour change programmes in Australia which address energy use, energy efficiency, energy conservation and demand management focusing particularly on the residential sector. This is followed by a review of programmes using the framework of analysis as outlined in the previous discussion (see also Table 1).

The research was limited to Australia and in particular the states of Victoria and South Australia as the research project partners were largely based in both these states. While the programme search was biased towards those targeting households many include those with a place based focus, those targeting businesses, schools and universities as well as those which had a broad agenda to encourage sustainable lifestyles. The intention was not to develop a 
comprehensive list of programmes across Australia but to gather together information on a broad range of initiatives to provide insight into the types of programmes being delivered, their aims and approaches, the organisations and levels of government involved and the types of techniques applied to assist in the behaviour change transition.

This review is based on information collected on over 100 programmes ranging from large scale education campaigns, local government light bulb and shower head exchange programmes to those that are community based involving a combination of different programmes. It was found that approximately $60 \%$ of programmes are being delivered by local and state governments, $35 \%$ and $25 \%$ respectively, with a small number of Federal Government programmes. Non-government organisations (NGOs) represented approximately $20 \%$ of programmes, while $10 \%$ are being delivered by businesses and the remaining delivered through church groups, universities and schools. The majority of NGOs involved in developing and delivering programmes are climate action groups or alliances and other environmental organisations.

Half of the programmes specifically target households with $10 \%$ of those targeting low income households. Another $30 \%$ have a community wide target audience which are generally place based and may target different sectors across a particular region. Approximately $10 \%$ of programmes targeted the business sector, primarily small to medium enterprises and another $7 \%$ of programmes were internally focused local government programs.

The following list of categories of aims and approaches (see below) has emerged as a result of reviewing the broad list of programmes. Each programme has been categorised according to the descriptions of aims and approaches derived from their websites and other material provided by the organisation or if not clearly stated, some assumptions have been made by the researchers as to the dominant approach adopted.

\section{Programme Aim Categories}

\section{Energy use:}

Programmes aiming at reducing energy use through behaviour change, equipment and technological change, improving energy efficiency, or changing the source of energy from coal fired plants to solar or other renewables. Energy use is then broken down into which programmes target households, community, commercial sector, council or renewables.

\section{Sustainable-lifestyles:}

Programmes focussed on broad, long term influence on behaviour around water, energy, consumption, transport etc., broad environmental goals but aimed at household/community level.

\section{Resource efficiency:}

Programmes that go beyond energy efficiency but target changes to how resources more broadly are used (including energy, water, waste, pollution). Resource efficiency is then

\section{General Approach Categories}

Audits:

Main thrust of the programme uses auditing of a home or business usually regarding energy.

Capacity building:

Involves education, skill acquisition, training, supply of material and equipment.

\section{Commitment:}

Target setting, sign up, pledging, reporting or allowing monitoring of a programme.

\section{Education:}

Engaging the audience with information, workshops and forums. May include home based engagement techniques through auditing for example.

Equipment/appliance change:

Replacement of energy wasting appliances or equipment.

Energy Infrastructure:

Shifting from coal fired to renewable 
broken down into those programmes that focus only on energy and water, buildings, SMEs and recycling.

\section{Transport:}

Programmes focussed on changing mode of transport used.

\section{Water:}

Programmes focussed on changing water use levels. energy production.

\section{Information:}

Supply of kits, checklists, written material, etc.

Retrofit assistance:

Guidance and/or material supply to enable greater energy efficiency of the building envelope.

Sustainable Housing Development:

Creating the housing and overall development to be energy efficient and mostly energy self sufficient as well as resource efficient.

Training:

Programmes providing particular skill sets to participants.

Over 50 percent of all programmes are primarily concerned with reducing energy use and half of those focus on energy use within the home. Almost a quarter of all programmes are aimed at encouraging sustainable lifestyles again largely targeting individuals and households with a number targeting the broader community. Most of the remaining programmes focus on resource efficiency. Figure 1 illustrates the relationship between programmes aims and the spectrum of approaches broadly adopted, from information only programmes to community based capacity building programmes. It shows that the emphasis in energy use programmes is on the use of retrofitting and auditing while sustainable lifestyle programmes have more of an education, capacity building and information provision emphasis. Programmes focusing on resource use also have a more technical emphasis around retrofits, appliance replacement or infrastructure projects. It is worth noting that few programs are about the provision of information only, information provision is generally combined with other education techniques such as workshops, training and forums. Information is also a key component of most energy audit processes.

\section{Figure 1: Programmes by Aim and General Approach}

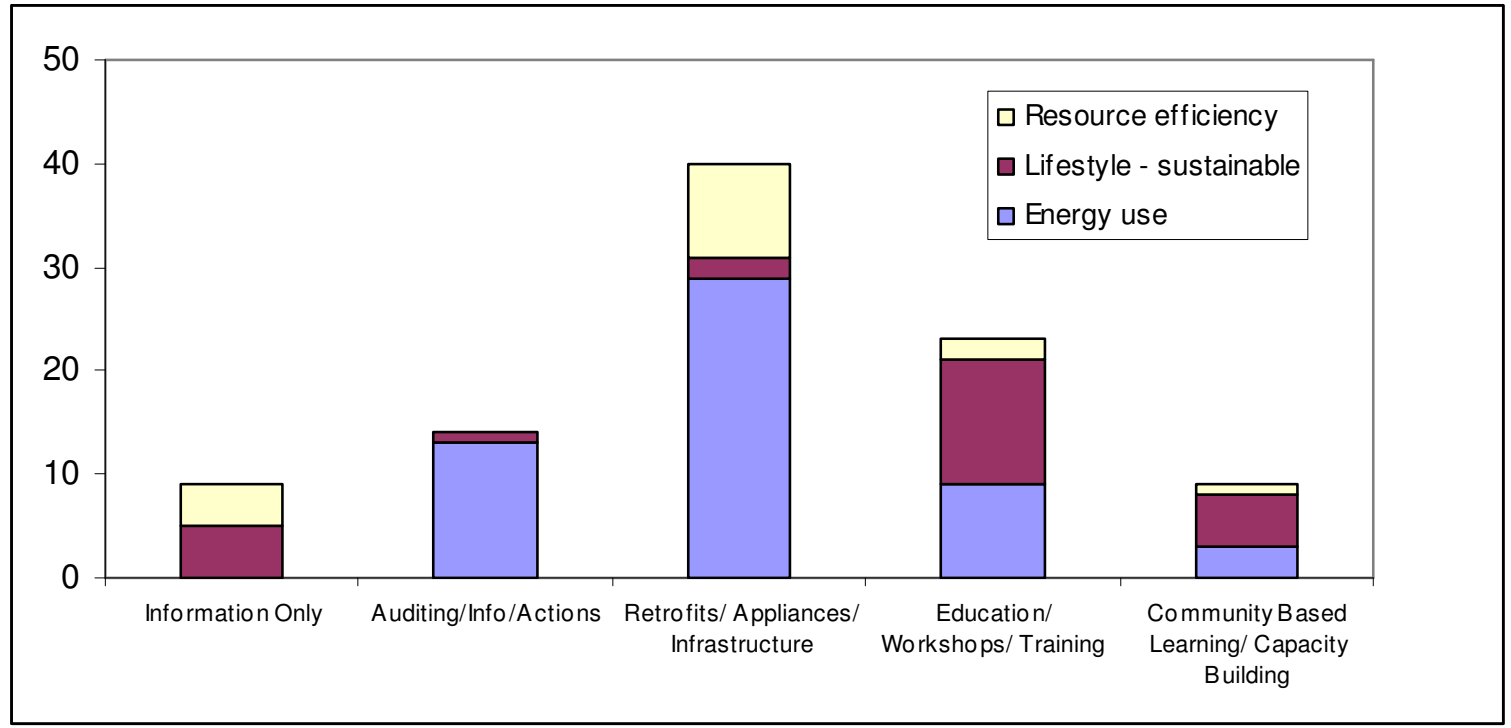


Table 2 summarises the range of programmes by target audience, focus and approach. Programmes which target communities largely adopt education based techniques including workshops, events and forums and importantly some include a combination of other approaches to foster capacity building within communities such as supporting the formation of working groups, offering leadership programs, outreach to other community organisations, technical assistance and advice, infrastructure programmes such as bulk purchasing of solar panels as well as offering auditing and retrofitting. Those programmes targeting households have an education and awareness raising emphasise through information provision and workshops with those focused on energy use predominantly offering home auditing services and some basic retrofitting.

Table 2 Programme by Audience, Programme Focus and Approach

\begin{tabular}{|c|c|c|}
\hline Audience & Programme Focus & General Approach \\
\hline Households & $\begin{array}{l}50 \% \text { focus on energy } \\
\text { use; } 30 \% \\
\text { sustainable- } \\
\text { lifestyles; } 10 \% \\
\text { resource efficiency; } \\
8 \% \text { transport; }\end{array}$ & $\begin{array}{l}\text { Emphasis on use of } \\
\text { auditing and retrofits } \\
\text { for energy use. Those } \\
\text { focusing on sustainable } \\
\text { lifestyles use a number } \\
\text { of education } \\
\text { techniques including } \\
\text { forums, workshops, } \\
\text { courses etc. Also use of } \\
\text { social support, goal } \\
\text { setting and } \\
\text { commitment } \\
\text { procedures. }\end{array}$ \\
\hline $\begin{array}{l}\text { Low income } \\
\text { households }\end{array}$ & $\begin{array}{l}\text { Focus is on energy } \\
\text { use and resource } \\
\text { efficiency - energy } \\
\text { and water }\end{array}$ & $\begin{array}{l}\text { Audits, retrofits and } \\
\text { education }\end{array}$ \\
\hline Community & $\begin{array}{l}\text { Focus mainly on } \\
\text { energy use across } \\
\text { range of sectors and } \\
\text { sustainable lifestyles }\end{array}$ & $\begin{array}{l}\text { Similar approaches to } \\
\text { those adopted for } \\
\text { households - multiple } \\
\text { techniques used, some } \\
\text { include technical and } \\
\text { behavioural, some } \\
\text { focus on capacity } \\
\text { building broadly. }\end{array}$ \\
\hline Business & $\begin{array}{l}60 \% \text { focus on } \\
\text { resource efficiency } \\
\text { and } 40 \% \text { on energy } \\
\text { use }\end{array}$ & $\begin{array}{l}\text { Primarily focus on } \\
\text { raising awareness, } \\
\text { education and audits or } \\
\text { assessments. }\end{array}$ \\
\hline Councils & $\begin{array}{l}50 \% \text { focus on energy } \\
\text { use within council } \\
\text { operations, others } \\
\text { focus on resource } \\
\text { efficiency, transport } \\
\text { and water use }\end{array}$ & $\begin{array}{l}\text { Equipment and } \\
\text { appliance retrofits and } \\
\text { education, information } \\
\text { and audits }\end{array}$ \\
\hline Schools/Uni's & $\begin{array}{l}\text { Primarily focus is on } \\
\text { sustainable lifestyles } \\
\text { and one on transport }\end{array}$ & $\begin{array}{l}\text { Primarily information } \\
\text { sharing }\end{array}$ \\
\hline
\end{tabular}




\begin{tabular}{|l|l|l|}
\hline $\begin{array}{l}\text { Community } \\
\text { Groups }\end{array}$ & $\begin{array}{l}\text { Energy use in the } \\
\text { community }\end{array}$ & $\begin{array}{l}\text { Information and } \\
\text { training }\end{array}$ \\
\hline Individual & $\begin{array}{l}\text { Lifestyle - } \\
\text { sustainable }\end{array}$ & $\begin{array}{l}\text { Information and } \\
\text { education }\end{array}$ \\
\hline
\end{tabular}

\section{A Socio-technical Review of Current Practice in Australia}

The following comments on current practice in Australia according to the five themes that have emerged from the review of behaviour change and socio-technical research. This assessment is necessarily broad and qualitative at this stage. The previous overview of aims and approaches adopted by many programmes in Australia does provide some indication of the assumptions currently held about behaviour change, approaches to barriers and constraints, agency and empowerment, systemic changes and learning and integration. Further analysis would need to be carried out of each programme or by type of programme, to provide a more definitive assessment of the extent to which they address the issues raised under each theme and explore more fully the likelihood of success in achieving behavioural change and more importantly changes to systems, social practices, norms and standards.

\section{Framing Behaviour and Social Practices}

The majority of programmes targeting energy use within households emphasise auditing, retrofitting and information provision. While behavioural change may not be the primary focus in an auditing and retrofitting process, there is an assumption being made that this process is likely to raise people's awareness about their use of energy and water and that in turn they may modify their actions accordingly for example, by turning lights off not in use, switching off appliances on standby, replacing appliances and fittings with more efficient ones and so on. The extent to which these types of programmes explore behaviours and social practices beyond identifying the standard or perhaps tailored 'top ten' actions in the home is difficult to assess without further analysis but can be assumed to be highly unlikely.

Those programmes which have a strong education and awareness raising emphasis offer workshops and training programmes aimed at achieving behavioural change which generally target a broad sweep of sustainable behaviours such as catching public transport, recycling, composting as well as energy and water consuming behaviours. These programmes are more likely to provide the opportunity for participants to explore and discuss their own practices and values and reflect on differing social norms and standards allowing for greater insights into the distinction between 'practical' and 'discursive consciousness' relating to habits and practices. Social pressure and peer support is more likely in these contexts which is also considered a necessary means to improving likelihood of behavioural change.

The extent to which behavioural change is being evaluated as a result of participating in such programs is typically done largely through self-reporting and analysis of energy bills. As was reported to the researchers in a number of discussions with organisations, these evaluation methods are flawed for a number of reasons. The accuracy of self-reporting is difficult to assess for programme co-ordinators. The short time frame for evaluations immediately after or during a series of workshops, means that results may show that participants do adopt a range of recommended actions and self report accordingly. The extent to which those actions are sustained or have implications in others areas of their life in difficult to assess after the participants leave the program and into the future. Use of web based feedback sites and virtual discussion groups is one way of providing participants with on-going peer support and may indicate the longer term impact of learning from workshops. Evaluation through use of energy 
bills is also a difficult indicator of behaviour change as there are often a range of factors affecting energy costs and usage from seasonal change to energy price increases making variations attributable to behavioural change difficult to assess. The transition towards changing and sustaining a new set of social practices rather than changing a few simple behaviours in the short term will be necessary to see significant reductions in environmental impact over time.

\section{Beyond barriers and constraints}

It is difficult to ascertain in this analysis the extent to which programmes explore or go beyond behavioural and technical barriers to changing behaviour. Home auditing and basic retrofitting programmes do address some technical barriers to reducing energy and water consumption through changing lights and shower heads and identifying other simple actions to carry out in the home. Beyond raising awareness around energy and water consuming activities it is largely left up to the individual or household to identify and overcome such behavioural barriers as breaking 'bad habits' and changing routines. The dynamic between providing technological fixes and challenging deeply entrenched values or routines is unlikely to be explored in these contexts particularly if home auditing processes are done as part of a 'small step' technical fix approach. If home audits are not done as part of a broader approach to raising awareness and changing social practices and routines combined with other systemic solutions then it is unlikely they will go beyond the barriers and constraints needed to support significant behaviour change.

A number of community based programmes which adopt more integrated approaches including technical or infrastructure changes with education, workshops and audits and have a longer term presence within a community are more likely to address the more challenging social, institutional and technical barriers and constraints. Community based programs also have the advantage of identifying locally specific barriers whether they are systemic, for example local regulations and infrastructure provision, or behavioural by exploring and challenging variations in social practices within their communities and as a result work with those communities to identify and tailor different approaches to addressing them. Ongoing support for the development of such programmes and community based organisations within a local area have the potential to address context specific barriers and with that invested time and knowledge also address wider systemic barriers and constraints influencing and shaping their own local context.

\section{Approaches to Agency and Empowerment}

Most programmes reviewed in Australia are being delivered by local and state governments as well as non-government organisations. The target audiences are largely individuals, households and communities with the primary aim of raising awareness and taking small steps to reduce energy and water consumption in the home. Technical solutions range from the dominant basic retrofitting and appliance replacement to bulk purchasing of solar panels to the more ambitious community based renewable energy projects. The extent to which local and non-government agencies are being supported by other key agencies including utility service providers or the federal government appears limited. The focus on individual and household focused solutions without wider systemic institutional and regulatory changes indicates that there is still a long way to go before broad scale changes can be achieved. These changes are necessary to reinforce the work of community organisations and strengthen agency and empowerment within communities.

Some community based programmes are actively seeking locally specific solutions to changing systems of energy provision and to an extent wider systems and institutions but on the whole 
the broad scale regulatory and systemic changes needed to support the sorts of transitions to social practices necessary to achieve significant reductions in resource consumption are yet to emerge. Those few programmes that have a capacity building emphasis are attempting to address issues of empowerment and agency within a community context. It could be argued that the process of engaging participants in collective education and behavioural change programmes is likely to improve an individual's sense of agency and control over their own contribution to greenhouse gas emissions. This type of engagement would be necessary on a broad scale however, if a significant challenge to social norms and systems is to be achieved. Empowering organisations and communities to make significant transitions in social norms which would reinforce a sense of collective agency requires the support and drive of wider scale institutional, regulatory and infrastructure changes.

\section{The Need for Systemic changes}

As highlighted earlier, assistance to address basic technical and behavioural changes are common to many programmes but changes to the systems of energy and water provision and fundamental challenges to commonly held values and social practices are much less evident. There are some examples of newly developing sustainable communities which aim to achieve a level of self sufficiency reflected in their building design and systems of energy and water provision which would support a set of environmentally sustainable practices amongst its inhabitants. These select communities may reveal many lessons about the technical and behavioural dynamic as they develop in the future. On another scale, however, is a federally funded solar energy programme aimed at supporting changes to systems of energy provision in particular regions across Australia. The extent to which either of these types of programmes will have wider implications for broad scale systemic change is yet to be seen. On a much wider scale, new mandatory renewable energy targets as well as the introduction of a cap and trade system are also yet to be tested as to their implications for changing social practices and norms. The current context in Australia for the programmes reviewed here is that they are all operating in an ad hoc and largely uncoordinated manner each developing their own targets, agendas and approaches. While locally generated and delivered programmes dominate and may be most effective in achieving solutions and changes specific to their contexts, the support of wider systemic changes and standards are necessary to drive ongoing and broad scale changes in the future.

\section{Paths through learning and integration}

The sorts of approaches to education and learning reflected in many programmes to some extent highlights the assumption that providing information and raising awareness will lead to behavioural change. This is not to say that information alone is the dominant approach. Many programmes adopt an education based model which may include workshops, training sessions, forums and community events. Those programmes targeting energy use within the home largely adopt the auditing and basic retrofits approach which to some extent is likely to increase levels of awareness but may not necessarily lead to behavioural change and sustained learning. Those programmes with a workshop component are significantly more likely to achieve a greater level of engagement and learning however the extent to which that translates into behavioural changes is also difficult to assess. Those community based programmes often driven by locally based climate action groups perhaps with the support of local government, appear to offer the most scope for integrating a number of approaches to achieving both technical and behavioural change. The ongoing and socially embedded nature of locally driven programmes such as these has allowed, in some cases, for a number of iterations of their programmes and as a result through 'trial and error' they are identifying the sorts of solutions required to achieve sustained change. Some of these organisations have achieved significantly high levels of learning not only about delivering programmes but about the communities in 
which they are working. These few organisations represent the key leaders in learning in the field of climate action and engaging communities on environmental issues. The extent to which these types of programmes can be replicated in other communities is worthy of further investigation. Certainly it appears that some of the learning from these key organisations is being applied in other local contexts as newly formed organisations adopt similar approaches to those developed through more established programmes. These community based examples appear to best reflect what could be constituted as 'social learning in practice' and warrant further investigation.

\section{TOWARDS LOW CARBON COMMUNITIES - DIRECTIONS FOR POLICY AND PROGRAMME DESIGN}

Transitioning to low carbon communities will require shifts in social practices and the norms and values which shape them. 'Normalised' pro-environmental behaviours will occur hand in hand with particular changes to the infrastructures, institutional arrangements and systems of governance which shape and reinforce social practices. To identify what is necessary to assist in the transition to low carbon communities we need to understand the dynamic relationship between the formation of social practices and the contexts in which they exist. The current dominance of the 'rational choice model' of consumer behaviour which is reinforced by the 'techno-economic' model of change prioritises technological solutions and is preoccupied with the individualisation of responsibility for environmental problems. This has given rise, on the one hand, to a range of technological solutions which have not sufficiently or explicitly taken account of social practices and social contexts and therefore have not resulted in the expected energy efficiency gains (e.g. pricing signals and energy efficient appliances) and, on the other hand, to the emergence of a plethora of behaviour change programmes designed to assist individuals, households and businesses identify the steps they can take to reduce their energy, water and resource consumption. Channelling policy and programme development towards individualised behaviour change is misguided without also addressing the broad regulatory, institutional and social setting in which those behaviours form.

Current approaches to behaviour change programmes largely targeting energy use in households in the Australian context may typically also include a home energy audit, some basic retrofits (e.g. lighting and shower heads), the provision of information and a list of key actions for individuals to adopt. In this study, many programmes with the broad aim of encouraging sustainable lifestyles were found to adopt education based techniques including the use of workshops, forums and community events. The majority are delivered through local and state governments as well as non-government organisations. The relatively few community based programmes reviewed were found to have been developed by volunteer driven climate action or environmental groups, and were the most likely to adopt a combination of approaches to addressing both technical and social dimensions of change. This is perhaps a reflection of the socially embedded nature of many of these groups, the knowledge of their local communities, the strength of relationships they have built up over time, their role in advocating for local needs and the opportunity they develop in trialling and adapting a range of approaches over time which best suit their local contexts.

While this paper does not advocate a standard template for programmes aimed at changing behaviour, the research indicates that there are critical factors that could usefully be considered when developing behaviour change programmes. Moreover, if behaviour change programmes are to achieve sustained changes to social practices, broader systemic changes will invariably also be required. The review of behaviour change and socio-technical literature led to the identification of five themes for policies and programmes: behaviour and social practices; barriers and constraints; agency and empowerment; systemic changes; and learning and integration. There is a critical role for government at the national, state and local level to coordinate and better integrate current approaches to both the technical and social transitions needed to address climate change. It is not enough to just expect people to 'just try harder' through 
taking 'small steps', without addressing the systemic nature of both environmental problems and daily practices.

Governments shape institutional and infrastructure systems. They also play a critical role in supporting community based organisations and practices, through systemic support structures, funding models, infrastructure projects and policy and regulatory mechanisms. While climate action groups and other environmental organisations have a role in assisting the transition to low carbon communities, their ongoing work will need the support of government to be sustained, and will also rely on the necessary wider systemic changes which governments can effect. The next stage of this research will further explore a selection of key programmes and organisations identified in this review. The intention is to examine in more depth the questions that have emerged within each of the five themes highlighted in this paper which it is hoped will give further insight into what is necessary to make the transition towards low carbon communities. 


\section{REFERENCES}

Australian Psychological Society, (2008) Climate Change: What You Can Do. 'Common Reactions to learning about Severe Environmental Problems' section, Australian Psychological Society, viewed 7/04/08 <http://www.psychology.org.au/publications/tip_sheets/climate/ >

Brown, Valerie A. (2008) Leonardo's Vision: A Guide to Collective Thinking and Action, Sense Publishers, Rotterdam, The Netherlands.

Bulkeley, H., Watson, M. and Hudson, R. (2007) Modes of governing municipal waste. Environment and Planning A, 39, 2733-2753.

Chappells, H. Klintman, M. Linden, A-L. Shove, E. Spaargaren, G and Bas van Vliet (2000) Domestic Consumption Utility Services and the Environment: Final Domus Report Feb 2000, final report of an EU DGXII project, ENV-CT97-0467, Universities of Lancaster and Wageningen and Lund.

Chappells, H., and Shove, E. (2005) 'Debating the future of comfort: environmental sustainability, energy consumption and the indoor environment' Building Research and Information 33(1) pp. 32-40.

Costanzo, M. Archer, D, Aronson, E \& Pettigrew, T (1986) Energy Conservation behaviour: the difficult path from information to action, American Psychologist, vol.41, no.5, p521-8

Crosbie, T. (2006) Household Energy Studies: the gap between theory and method, Energy and Environment, Vol.17, No.5., p735-753.

Crosbie,T., Stokes, M. and Guy, S. (2008) Illuminating Household Energy Demand and the Policies for its Reduction, Energy and Environment, Vol. 19. No.7. p.979-993

DEFRA, Department for Environment, Food and Rural Affairs (2008) A Framework for ProEnvironmental Behaviours, London UK.

MacKenzie-Mohr, D. and Smith W. (1999) Fostering Sustainable Behavior: An Introduction to Community Based Social Marketing, New Society Publishers, US.

De Kirby, K., Morgan, P., Norhaus, T. and Shellenberger, M. (2007) Irrationality wants to be your friend, in J. H. Isham and S. A. Waage (eds) Ignition: What You can Do to Fight Global Warming and Spark a Movement, Island Press, Washington DC, Ch 4

De Young, R. (1996). "Some psychological aspects of reduced consumption behavior: The role of intrinsic satisfaction and competence motivation", Environment and Behavior, 28 (3), pp. 358-409.

Dietz, T. and Stern. P. (eds) (2002) New Tools for Environmental Protection, National Academies Press, Washington D.C.

Fien, J., Scott, W. and Tilbury, D. 2002. Exploring principles of good practice: learning from a metaanalysis of case studies on education within conservation across the WWF Network. Applied Environmental Education and Communication, 153-162.

Fien J., Horne, R. and Moloney, S. (2008) "Carbon Neutral Communities: The Role of Social Learning”, a chapter in the forthcoming Climate Change Responses Across Australia: Social Learning and Adaptation, Australian Academy of Social Sciences.

Finger, M (1993) Does environmental learning translate into more responsible behaviour, Nature Herald, May, p. 9-10. 
Jackson, T. (2005) Motivating Sustainable Consumption: A review of evidence on consumer behaviour and behavioural change, A Report to the Sustainable Development Research Network, Sponsored by Defra UK.

Guy, S (2006) 'Designing urban knowledge: competing perspectives on energy and buildings', Environment and Planning C: Government and Policy 2006, Vol 24, pg.645-659.

Heimlich, J. E. and Ardoin, N. M. (2008). Understanding behaviour to understand behaviour change: a literature review. Environmental Education Research, 14(3), 215-237.

Hobson, K. (2006) Competing Discourses of Sustainable Consumption: Does the 'Rationalisation of Lifestyles' Make Sense? In Jackson, T. (Ed.) The Earthscan Reader on Sustainable Consumption., Earthscan, London.

IPCC (2001) Third Assessment Report: Climate Change 2001. IPCC, UNEP.

Kaplan, S. (2000) Human nature and environmentally responsible behaviour, Journal of Social Issues, 56 (3) pp.491-508.

Keen, M., Brown, V.A. and Dyball, R (eds.) (2005) Social Learning in Environmental Management: Towards A Sustainable Future, Earthscan, London.

Kollmuss, A. and Agyeman, J. (2002). Mind the Gap: why do people act environmentally and what are the barriers to pro-environmental behaviour? Environmental Education Research, 8(3), 239-260.

Leeuwis, C. and Pyburn, R. (eds.) (2002) Wheel-barrows full of frogs: social learning in rural resource management, Koninklijke Van Gorcum, Assen, The Netherlands.

Lutzenhiser, L. (1993) 'Social and Behavioural Aspects of Energy Use', Annual Review of Energy and Environment, 18, 247-289

Maniates, M. (2002) Individualisation: plant a tree, buy a bike, save the world?, in Thomas Princen, Michael Maniates and Ken Conca (eds), Confronting consumption, MIT Press Cambrige.

O’Dwyer, W., Leeming, F., Cobern M., Porter B., and Jackson, J.M. (1993) Critical Review of Behavioural Interventions to Preserve the Environment - Research Since the 1980s, Environment and Behaviour Vol. 25, No.3 May 1993. p.275-321.

Productivity Commission (2005) The Private Cost Effectiveness of Improving Energy Efficiency, Productivity Commission, Melbourne.

Schmidt, Chris R. (2004) The Politics of International Law, Cambridge University Press, Cambridge, UK.

Shipworth, M. 2000. Motivating Home Energy Action: A handbook of what works. In AGO, Canberra, 150.

Shove, E. (2003) Comfort, Cleanliness and Convenience: The Social Organisation of Normality, Berg Publishers, Oxford and NY.

Shove, E. (2004) 'Efficiency and Consumption: Technology and Practice', Energy and Environment, 15(6): 1053-1065. 
Shove, E. (2006) Chapter 20 Efficiency and Consumption: Technology and Practice, p.293 in Jackson, T (Ed.) (2006) The Earthscan Reader in Sustainable Consumption, Earthscan, UK and USA

Shove, E. and Warde, A (2001) 'Inconspicuous Consumption: The sociology of consumption, lifestyles and the environment', in R. Dunlap, F. Buttel, P. Dickens, and A Gijswijt (eds) Sociological Theory and the Environment: Classical Foundations, Contemporary Insights, Rowman and Littlefield, Lanham, MD, p. 230-241.

Shove, E., Watson, M., Hand, M. \& Ingram, J. (2007) The Design of Everyday Life, Oxford: Berg

Shove, E., Chappells, H., Lutzenhiser, L., and Hackett, B. (2008) 'Comfort in a Low Carbon Society' Editorial of the Special Issue of Building Research and Information 36(4) 307-311.

Slob A. and Verbeek P-P. (2006) "Technology and User Behaviour", Chapter 1 in Verbeek P-P. and A. Slob (eds.) (2006) User Behaviour and Technology Development: Shaping Sustainable Relations Between Consumers and Technologies, Springer.

Smith, J.-A. 2004. Obtaining Behaviour Change Not Just Raising Awareness. In National Australian Association of Environmental Education Conference. Adelaide.

Southernton, D, Warde, A and Hand, M (2004) The Limited Autonomy of the Consumer: implications for sustainable consumption' in Southerton, D. Chappells, H. and van Vliet, B (eds) Sustainable Consumption: The Implications of Changing Infrastructures of Provision, Edward Elgar, Cheltenham, $\mathrm{p}$. $32-48$.

Southerton, D. Chappells, H. and van Vliet, B (eds) (2004) Sustainable Consumption: The Implications of Changing Infrastructures of Provision, Edward Elgar, Cheltenham.

Stern, P.C. (2000) Toward a coherent theory of environmentally significant behaviour, Journal of Social Issues, Vol. 56, No.3., p. 407-424.

Stijbos, S. (2006) "A Normative Systems Approach for Managing Technology and Collective Human Action", Chapter 34 in Verbeek P-P. and A. Slob (eds.) (2006) User Behaviour and Technology Development: Shaping Sustainable Relations Between Consumers and Technologies, Springer.

UK Green Building Council (2008) Issues Paper: Behaviour Change - current status and barriers analysis, Energy Efficiency Partnership for Homes, Sustainable Development Commission and the Technology Strategy Board.

Van der Waals, J., Vermeulen, W., Glasbergen, P. (2003) 'Carbon Dioxide Reduction in Housing: Experiences in Urban Renewal Projects in the Netherlands', Environment and Planning C: Government and Policy, 21, pp. 411-427

Verbeek P-P. and A. Slob (eds.) (2006) User Behaviour and Technology Development: Shaping Sustainable Relations Between Consumers and Technologies, Springer.

Wallace, C (2002) 'Household Strategies: Their Conceptual Relevance and Analytical Scope in Social Research', Sociology, 36 (2): 275-292

Wals, A.E.J. (ed) (2007) Social Learning: towards a sustainable world, Wageningen Academic Publishers, the Netherlands.

Wilhite, H., Shove, E., Lutzenhiser, L., Kempton, W (2000) 'Twenty Years of Energy Demand Management: We Know more about Individual Behaviour, but how much do we really know about 
Demand?', In: 2000 Proceedings of the American Council for an Energy Efficient Economy, Washington DC. pp 8435-8453

Winefield, J. 2005. Recommendations for behaviour change programs to reduce greenhouse impacts in $S A$. Office of Sustainability, Adelaide, SA.

World Wildlife Fund - WWF (2008) Weathercocks and Signposts: The environment movement at a crossroads, Surrey UK. 